\title{
Continuously elevated concentrations of oxytocin during milking are necessary for complete milk removal in dairy cows
}

\author{
BY RUPERT M. BRUCKMAIER, DIETER SCHAMS* AND JÜRG W. BLUM \\ Institut für Tierzucht der Universität Bern, CH-3012 Bern, Schweiz \\ *Institut für Physiologie der Technischen Universität München, \\ D-85354 Freising-Weihenstephan, Deutschland
}

(Received 25 February 1993 and accepted for publication 5 August 1993)

\begin{abstract}
Summary. The importance of elevated concentrations of oxytocin (OT) during the entire milking period was investigated in seven primiparous dairy cows with inherent disturbed milk ejection and in sixteen healthy cows with disturbed milk ejection induced by placing them in an operating theatre. Disturbance of milk removal in both groups has previously been demonstrated to be exclusively due to central blockage of the expected O'T release in response to teat stimulation and milking. However, milk ejection can be induced by exogenous OT. OT (0.2 i.u.) was injected i.v . before milking and $49 \pm 6 \%$ of the total milk was removed. When plasma O'T decreased, milk flow stopped. In response to a second and third injection of $0 \cdot 2 \mathrm{i} . \mathrm{u}$. $\mathrm{OT}, 30 \pm 4$ and $7 \pm 2 \%$ of the milk were removed respectively. The remaining milk was removed with $10 \mathrm{i} . \mathrm{u}$. OT. The lag time from injection of OT to the start of milk flow was inversely correlated with the amount of milk actually removed in response to the O'T injection. If $0 \cdot 2 \mathrm{i} . \mathrm{u}$. OT was injected during intramammary pressure (IMP) recording, IMP immediately increased to its maximum value. After $2.5 \pm 0.3 \mathrm{~min}$, IMP decreased to an intermediate IMP (between preinjection and maximum IMP). After two additional injections of $0.2 \mathrm{i} . \mathrm{u}$. OT and after injection of $0.5 \mathrm{i} . \mathrm{u}$. OT, IMP increased to a similar maximum. However, after injection of 0.5 i.u. OT, maximum IMP lasted longer (2.9 $\pm 0.3 \mathrm{~min} ; P<0.05)$ than after injections of 0.2 i.u. If OT was continuously infused $(0 \cdot 15 \mathrm{i} . \mathrm{u} . / \mathrm{min})$ during milking, milk flow lasted until the udder was completely emptied. IMP increased during OT infusion to a maximum which remained stable until infusion was stopped after $10 \mathrm{~min}$. The same IMP maximum was reached after the first individual OT injection $(0 \cdot 2 \mathrm{j} . \mathrm{u}$.), but when plasma $\mathrm{OT}$ decreased towards basal concentrations, milk flow ceased and IMP decreased to an intermediate level. Thus continuously elevated OT concentrations such as those during infusion or during normal milking are necessary for complete milk removal.
\end{abstract}

Elevated concentrations of oxytocin (OT) during milking are needed for ejection of alveolar milk, i.e. shifting of the main milk fraction (which is fixed by adhesive and capillary forces) into the cisternal cavities for milk removal (Sagi et al. 1980; Mayer et al. 1984b; Schams et al. 1984; Gorewit \& Gassman, 1985). OT is released in response to manual or mechanical teat stimulation, i.e. during premilking stimulation and milking (Sagi et al. 1980; Mayer et al. 1984a,b; Schams et al. 1984; Gorewit \& Gassman, 1985; Mayer et al. 1985; Lefcourt \& Akers, 1991; Mayer et al. 1991; Gorewit et al. 1992). Both endogenous and exogenously administered OT cause 
alveolar milk ejection, an increase of intramammary pressure (IMP) within the cistern (Bruckmaier et al. 1991; Mayer et al. 1991) and an enlargement of the cisternal volume (Bruckmaier \& Blum, 1992). Premilking teat stimulation causes the release of OT and evokes milk ejection before milking begins; this is important for fast and complete milk removal (Sagi et al. 1980; Mayer et al. 1984b; Gorewit \& Gassman, 1985). Although OT is released during the whole milking procedure (Schams et al. 1984; Mayer et al. 1991), it has not been shown whether a continuously elevated OT concentration is necessary for continuous and complete milk removal. Thus, it was not known until now whether the alveolar milk is completely ejected in response to premilking stimulation or whether milk is ejected during the whole milking procedure in response to continuously elevated concentrations of OT.

In recent investigations, central inhibition of milk ejection, i.e. lack of OT release, was demonstrated in dairy cows. An absence of OT release in response to teat stimulation and machine milking was found in primiparous parturient cows with disturbed milk removal (Bruckmaier et al. 1992) and in healthy cows if disturbed by placing them in unfamiliar surroundings (Bruckmaier et al. 1993). Because exogenous OT in physiological amounts completely normalized milk removal in these animals, a reduced effect of $\mathrm{O}^{\prime} \mathrm{T}$ at the level of the mammary gland (peripheral disturbance) could be excluded. Because manual teat stimulation and teatcup liners were found not to induce OT release in these animals, milk ejection can be manipulated by exogenous OT. Based on these findings, the hypothesis could be tested that release of OT at the start of milking, which causes a maximal increase of IMP (Mayer et al. 1991), is not sufficient to shift the whole amount of alveolar milk into the cistern. Previous investigators have considered that on the contrary the OT release during prestimulation and early milking is the most important factor for complete milk ejection (Mayer et al. 1984b, 1985; Schams et al. 1984). The goal of this work was to show the importance of continuously elevated OT concentrations during the whole milking procedure for continuous milk ejection when the cistern is continuously emptied by the milking machine. Experiments were designed to compare the effects on milk flow and IMP of repeated injections of OT, when blood OT is elevated only transiently after each injection, and of continuously infused OT, resulting in continuously elevated blood OT.

It was shown previously that the time from the start of premilking teat stimulation until milk ejection occurs increases during the course of lactation with decreasing amounts of milk being stored in the udder, although OT release was not delayed (Bruckmaier, 1988). The response time from OT release to milk ejection obviously depends on milk yield. Therefore, the lag time from injection of OT to the onset of milk flow and its dependence on the amount of ejected milk was investigated.

\section{MATERIALS AND METHODS}

\section{Animals and experimental procedures}

In Expt 1 (Table 1), seven primiparous parturient cows (Simmental $\times$ Red Holstein) with disturbed OT release located on different farms as described previously (Bruckmaier et al. 1992) were milked within $10 \mathrm{~d}$ after parturition and milk flow curves were recorded (Treatment 1.1) while OT (340 i.u./mg) was injected repeatedly before milking and during milking when milk flow had ceased. The IMP was recorded $1 \mathrm{~d}$ later during repeated OT injections, but for only four cows because of local hygienic conditions (Treatment 1.2). During IMP recordings, no milk was removed from the udder. In Expt 2 (Table 1), 16 cows (Simmental $\times$ Red Holstein) 


\section{Table 1. Experimental design of oxytocin treatments}

\section{Expt Animals \\ 1 Primparous parturient cows}

2 Cows in

unfamiliar surroundings

\author{
Treatment $n$ Measurements \\ 1.1
7 Milk flow, oxytocin conen

1.2

4 Intramammary pressure, oxytocin conen
4 Milk flow, oxytocin conch

4 Milk flow, oxytocin conen
4 Intramammary pressure, oxytocin concn

4 Intramammary pressure, oxytocin conen
Oxytocin administration: sequence of events

$0.2 \mathrm{i} . \mathrm{u}$. injected $3 \mathrm{~min}$ before milking; $0 \cdot 2,0 \cdot 2$ and $10 \mathrm{i} . u$. during milking when milk flow ceased

0.2 i.u. injected $2 \mathrm{~min}$ after teat cannulation; then $0 \cdot 2,0 \cdot 2$,

0.5 and 10 i.u. at $6 \mathrm{~min}$ intervals $0.2 \mathrm{i.u}$. injected $3 \mathrm{~min}$ before milking; $0 \cdot 2,0 \cdot 2,1.0$ and $10 \mathrm{i} . \mathrm{u}$. during milking when milk flow ceased

Milking until milk flow censed; $0.15 \mathrm{i} . \mathrm{u} . / \mathrm{min}$ infused until milk flow ceased; then 1.0 i.u. injected; then 10 i.u. injected when milk flow ceased

0.2 i.u. injected $2 \mathrm{~min}$ after teat cannulation; then $0 \cdot 2,0 \cdot 2$, $0 \cdot 5,1 \cdot 0$ and $10 \mathrm{i}$.u. at $6 \mathrm{~min}$ intervals

$0.15 \mathrm{i} . u . / \mathrm{min}$ infused for $10 \mathrm{~min}$ from $2 \mathrm{~min}$ after teat cannulation; $0 \cdot 2$ i.u. injected $7 \mathrm{~min}$ after and 10 i.u. $14 \mathrm{~min}$ after the end of infusion

in months 2-7 of their first to ninth lactations were studied during disturbed OT release by exposing them to the unfamiliar operating theatre of the research station (Bruckmaier et al. 1993). To avoid conditioning them to the unfamiliar surroundings, each animal was used once only in one of four treatments (Treatments 2.1-2.4). In Expt 2, OT was either repeatedly injected or continuously infused while milk flow or IMP was recorded. All experiments were performed between 15.30 and 18.00, i.e. at the approximate time of routine evening milking.

During milking, the milk removed was weighed continuously by a strain gauge system and milk flow curves were recorded as described previously (Schams et al. 1984; Bruckmaier, 1988; Bruckmaier et al. 1992). During IMP measurements, the pressure within the teat cistern was continuously recorded by inserting a steel cannula through the teat canal into the left front quarter. Pressure was transmitted through silastic tubing to a physiological strain gauge pressure transducer (Model P 23; Gould Inc., Oxnard, CA, USA) and the signal conveyed to a strip chart recorder. The pressure at the level of the teat base was calibrated to zero to eliminate influences of different teat lengths on the recorded pressure.

At $\sim 1 \mathrm{~h}$ before the experiments, indwelling catheters were inserted into both jugular veins to administer $\mathrm{OT}$ and to collect blood samples for determination of $\mathrm{O}^{\prime} \mathrm{T}$ concentrations. During the entire experiments, $10 \mathrm{ml}$ blood was taken every $1 \mathrm{~min}$. In Expt 2, an additional blood sample was taken $30 \mathrm{~s}$ after each injection of $\mathrm{O} T$ to measure the peak concentration of OT after injection more exactly.

\section{Laboratory methods}

Concentrations of OT were determined by radioimmunoassay as described previously (Schams, 1983). For technical reasons, O'T concentrations after the injection of 10 i.u. OT were not determined in this investigation. These concentra- 
tions have been found previously to be $>400 \mathrm{ng} / \mathrm{l} 1 \mathrm{~min}$ after injection, which is above the physiological range (our unpublished results).

\section{Statistical analyses}

Values are presented as means \pm SEM. Changes during the course of experiment were tested for significance $(P<0.05)$ by means of a paired $t$ test employing the UNIVARIATE procedure of the SAS program package, release 6.04 (SAS, 1990).

\section{RESULTS}

\section{Experiment 1. Primiparous parturient cows}

Treatment 1.1. Oxytocin injections during recording of milk flow. The concentration of OT (Table 2 ) increased $(P<0.05)$ within $1 \mathrm{~min}$ after the first OT injection $(0 \cdot 2$ i.u. $)$, then decreased immediately and reached almost basal concentrations before the succeeding OT injection. At the start of milking, OT concentration was $6.5 \pm 0.7 \mathrm{ng} / \mathrm{l}$. Because OT concentrations did not completely return to basal values before the next injection, both preinjection and postinjection OT concentrations increased moderately, but significantly, during the course of the experiment. Within $3 \cdot 5-4 \cdot 0 \mathrm{~min}$ after all injections of $0 \cdot 2$ i.u. OT, the OT concentration had fallen to half the value found after $1 \mathrm{~min}$.

Absolute and relative amounts of milk (Table 2) were highest after the first injection of OT and the start of machine milking, and decreased $(P<0.05)$ in response to the second and third injections of $0 \cdot 2$ i.u. OT. In response to the injection of $10 \mathrm{i} . \mathrm{u}$. OT, the amount of milk tended to increase again, but this was not significant.

The lag time from injection of OT to commencement of milk flow (Table 2) was not measured for technical reasons after the first injection of $0 \cdot 2$ i.u. OT. However, lag time increased $(P<0 \cdot 05)$ from the second to the third injection of $0 \cdot 2$ i.u. OT, and there was a strong correlation between the actual amount of milk removed and the lag time (Fig. 1). Because the correlation and regression coefficients for the second and third injections of $0 \cdot 2 \mathrm{i}$.u. OT were similar, the values from both were pooled to calculate the regression equation. Lag time decreased in a linear manner with increasing amounts of milk removed in response to injection. In response to the final injection of $10 \mathrm{i} . \mathrm{u}$. OT, lag time was shorter again (and the amount of milk higher) than after the third injection of $0 \cdot 2$ i.u.

Treatment 1.2. Oxytocin injections during recording of IMP. The concentration of OT increased $(P<0.05)$ in response to OT injection (Table 3). Preinjection and postinjection concentrations of OT (Table 2) increased slightly but significantly with increasing amounts of OT during the course of the experiment.

The IMP (Table 3) increased to a plateau in response to the first injection of 0.2 i.u. O'T, before decreasing again to another intermediate plateau between preinjection and postinjection pressure. In response to further injections of 0.2 and 0.5 i.u. OT, IMP increased again to a level similar to that after the first injection and decreased again to similar intermediate plateaux. In response to the injection of $10 \mathrm{i} . \mathrm{u}$. OT, however, the pressure increased to higher values than after the preceding injections.

Lag time from OT injection until IMP started to increase (Table 3) was similarly short in response to all injections. The duration of increase (Table 3) was longer after the first injection of 0.2 i.u. and after the injection of $10 \mathrm{i}$.u. OT as compared with the other injections $(P<0 \cdot 05)$. The duration of the IMP maximum (Table 3 ) was similar 
Table 2. Oxytocin concentrations, lag times from oxytocin injection to start of milk flow and milk fractions in response to oxytocin injections in primiparous parturient cows with disturbed oxytocin release (Treatment 1.1)

(Values are means $\pm \operatorname{sem}$ for $n=7$ )

Oxytocin injections, i.u....

First $0-2$

Second $0 \cdot 2$

Third $0 \cdot 2$

10

Oxytocin concn, ng/l

Before injection

1 min after injection

Lag time, min

Amount of milk

$\mathrm{kg}$

Percentage

$\begin{array}{cc}1 \cdot 6 \pm 0 \cdot 2^{\mathrm{a}} & 3 \cdot 1 \pm 0 \cdot 4^{\mathrm{b}} \\ 9 \cdot 7 \pm 0 \cdot 6^{\mathrm{a} *} & 12 \cdot 0 \pm 0 \cdot 3^{\mathrm{b} *} \\ \text { NH } & 0 \cdot 49 \pm 0 \cdot 06^{\mathrm{a}} \\ & \\ 4 \cdot 6 \pm 0 \cdot 7^{\mathrm{a}} & 2 \cdot 8 \pm 0 \cdot 4^{\mathrm{b}} \\ 49 \pm 6^{\mathrm{a}} & 30 \pm 4^{\mathrm{b}}\end{array}$

$3 \cdot 7 \pm 0 \cdot 3^{c}$
$13 \cdot 4 \pm 0 \cdot 3^{\mathrm{c} *}$
$0 \cdot 81 \pm 0 \cdot 04^{\mathrm{b}}$

$4 \cdot 0 \pm 0 \cdot 2^{c}$

$>400^{d}$

$0 \cdot 59 \pm 0 \cdot 05^{\mathrm{a}}$

NM, not measured for technical reasons.

a.b.c.d Values within line without common subscript letters were significantly different $(P<0 \cdot 05)$.

* Oxytocin concentrations before and after injection were significantly different $(P<0 \cdot 05)$.

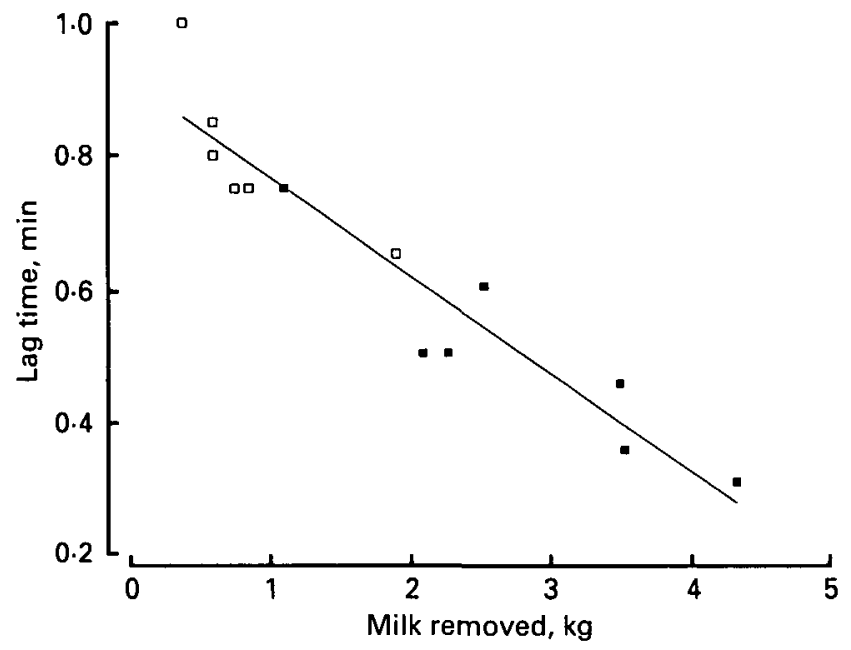

Fig. 1. Relationship between amount of milk $(x)$ removed in response to the second $(\square)$ and third ( $\square$ ) injection of $0.2 \mathrm{i}$.u. oxytocin and the lag time from injection until beginning of milk flow $(y)$ in primiparous parturient cows (Treatment 1.1 ; for details, see text.) The regression equation was $y=0.92-0.15 x, r=0.95, P<0.05$.

after all injections of 0.2 i.u., longer after injection of 0.5 i.u. $(P<0.05)$ and stable for $>10 \mathrm{~min}$ after injection of $10 \mathrm{i} . \mathrm{u}$. OT.

\section{Experiment 2. Cows in unfamiliar surroundings}

Treatment 2.1. Oxytocin injections during recording of milk flow. Concentrations of OT (Table 4) were highest within $0 \cdot 5-1 \mathrm{~min}$ of the first injection of $0 \cdot 2$ i.u. OT. Within 2 min after injection, the OT concentration started to decrease again. When the milking cluster was attached, OT concentration was $4 \cdot 4 \pm 0.7 \mathrm{ng} / \mathrm{l}$. Preinjection concentrations of OT increased slightly, and postinjection concentrations increased in a dose-dependent manner, until the end of the experiment. Fig. $2(a)$ shows typical results for an individual cow.

Absolute and relative amounts of milk (Table 4, Fig. $2 a$ ) were highest after the first injection of OT and the onset of machine milking, and decreased (similarly to Treatment 1.1 ) in response to the succeeding injections.

The lag time from injection of OT to commencement of milk flow (Table 3) 
Table 3. Oxytocin concentration, intramammary pressure, lag time from oxytocin injection to beginning of pressure increase, duration of pressure increase and of pressure maximum in response to oxytocin injections in primiparous parturient cows with disturbed oxytocin release (Treatment 1.2)

(Values are means $\pm \operatorname{sem}$ for $n=4$ )

$\begin{array}{llllll}\text { Oxytocin injections, i.u... } & \text { First } 0.2 & \text { Second } 0 \cdot 2 & \text { Third } 0 \cdot 2 & 0.5 & 10\end{array}$

\begin{tabular}{|c|c|c|c|c|c|}
\hline \multicolumn{6}{|l|}{ xytocin conen, ng/l } \\
\hline Before injection & $1 \cdot 8 \pm 0 \cdot 3^{\mathrm{B}}$ & $2 \cdot 9 \pm 0 \cdot 3^{\mathrm{ab}}$ & $2 \cdot 9 \pm 0 \cdot 2^{\mathrm{ab}}$ & $3 \cdot 8 \pm 0 \cdot 1^{b}$ & $3 \cdot 6 \pm 0 \cdot 2^{b}$ \\
\hline $1 \mathrm{~min}$ after injection & $11 \cdot 6 \pm 0 \cdot 8^{n *}$ & $12 \cdot 2 \pm 0 \cdot 4^{\mathrm{a} *}$ & $12 \cdot 4 \pm 0 \cdot 3^{a} *$ & $32 \cdot 1 \pm 2 \cdot 4^{b *}$ & $>\mathbf{4} 00^{\mathrm{c} *}$ \\
\hline \multicolumn{6}{|l|}{ Intramammary pressure, $\mathrm{kPa}$} \\
\hline Before injection & $3 \cdot 4 \pm 0 \cdot 7^{\mathrm{u}}$ & $5 \cdot 3 \pm 0 \cdot 6^{b}$ & $5 \cdot 4 \pm 0 \cdot 6^{b}$ & $5 \cdot 4 \pm 0 \cdot 6^{b}$ & $5 \cdot 3 \pm 0 \cdot 6^{13}$ \\
\hline Maximum after injection & $6 \cdot 4 \pm 0 \cdot 5^{\mathrm{a} *}$ & $6 \cdot 4 \pm 0 \cdot 6^{\mathrm{a} *}$ & $6 \cdot 4 \pm 0 \cdot 5^{\mathrm{a} *}$ & $6 \cdot 5 \pm 0 \cdot 6^{n} *$ & $7 \cdot 2 \pm 0 \cdot 5^{\mathrm{b} *}$ \\
\hline Lag time, $\min$ & $0 \cdot 30 \pm 0.02^{\mathrm{a}}$ & $0 \cdot 36 \pm 0.03^{\mathrm{a}}$ & $0 \cdot 32 \pm 0 \cdot 05^{\mathrm{a}}$ & $0 \cdot 30 \pm 0 \cdot 02^{\mathrm{a}}$ & $0 \cdot 33 \pm 0.02^{\mathrm{a}}$ \\
\hline Duration of increase, $\min$ & $0 \cdot 33 \pm 0.05^{\mathrm{a}}$ & $0 \cdot 26 \pm 0.05^{b}$ & $0 \cdot 19 \pm 0 \cdot 02^{\mathrm{b}}$ & $0 \cdot 24 \pm 0 \cdot 04^{\mathrm{b}}$ & $0 \cdot 33 \pm 0.06^{\mathrm{a}}$ \\
\hline Duration of maximum, min & $2 \cdot 49 \pm 0 \cdot 35^{\mathrm{a}}$ & $2 \cdot 40 \pm 0 \cdot 37^{\mathrm{a}}$ & $2 \cdot 35 \pm 0 \cdot 47^{\mathrm{a}}$ & $2.92 \pm 0 \cdot 32^{\mathrm{b}}$ & $>10$ \\
\hline
\end{tabular}

a.b.c Values within line without common subscript letters were significantly different $(P<0.05)$.

* Intramammary pressure before and after injection was significantly different $(P<0 \cdot 05)$.

Table 4. Oxytocin concentration, lag time from oxytocin injection to beginning of milk flow and milk fractions in response to oxytocin injections in cows with oxytocin release disturbed by unfamiliar surroundings (Treatment 2.1)

(Values are means \pm sem for $n=4$ )

\begin{tabular}{|c|c|c|c|c|c|}
\hline Oxytocin injections, i.u.... & First 0.2 & Second $0 \cdot 2$ & Third 0.2 & 1 & 10 \\
\hline \multicolumn{6}{|l|}{ Oxytocin conen, ng/l } \\
\hline Before injection & $1 \cdot 6 \pm 0 \cdot 3^{a}$ & $2 \cdot 3 \pm 0 \cdot 5^{\mathrm{ab}}$ & $2 \cdot 8 \pm 0 \cdot 6^{\mathrm{ab}}$ & $3 \cdot 2 \pm 0 \cdot 3^{b}$ & $3 \cdot 8 \pm 0 \cdot 3^{c}$ \\
\hline $1 \mathrm{~min}$ after injection & $9 \cdot 9 \pm 1.9^{2 *}$ & $9 \cdot 1 \pm 0 \cdot 9^{a *}$ & $10 \cdot 3 \pm 1 \cdot 3^{\mathrm{a} *}$ & $32 \cdot 3 \pm 3 \cdot 7^{\mathrm{b} *}$ & $>400^{\mathrm{c} *}$ \\
\hline Lag time, $\min$ & NM & $0.55 \pm 0.06^{\mathrm{a}}$ & $0 \cdot 83 \pm 0.09^{b}$ & $0 \cdot 65 \pm 0 \cdot 06^{\mathrm{ab}}$ & $0 \cdot 70 \pm 0 \cdot 04^{\mathrm{b}}$ \\
\hline \multicolumn{6}{|l|}{ Amount of milk } \\
\hline $\mathrm{kg}$ & $4 \cdot 5 \pm 0 \cdot 2^{\mathrm{a}}$ & $2 \cdot 6 \pm 0 \cdot 3^{b}$ & $1.2 \pm 0.5^{\mathrm{bc}}$ & $0.5 \pm 0.05^{\mathrm{c}}$ & $0.4 \pm 0.08^{c}$ \\
\hline Percentage & $49 \pm 2^{\mathrm{a}}$ & $2 \overline{9} \pm 4^{\mathrm{b}}$ & $13 \pm 4^{\mathrm{bc}}$ & $5 \pm 1^{c}$ & $4 \pm 1^{c}$ \\
\hline
\end{tabular}

NM, not measured for technical reasons.

a, b. c Values within line without common subscript letters were significantly different $(P<0 \cdot 05)$.

* Oxytocin concentrations before and after injection were significantly different $(P<0.05)$.

increased $(P<0.05)$ from the second to the third injection of $0.2 \mathrm{i} . \mathrm{u}$. O'T (to levels similar to those in Treatment 1.1). After injection of 1 and 10 i.u. OT, lag time tended to be even shorter, but this change was not significant.

Treatment 2.2. Oxytocin infusion during recording of milk flow. Premilking concentrations of OT were $1 \cdot 8 \pm 0.5 \mathrm{ng} / \mathrm{l}$; they remained basal during early milking, and were $2.0 \pm 0.5 \mathrm{ng} / \mathrm{l}$ at the start of OT infusion. During infusion, plasma concentrations of OT increased $(P<0.05)$ continuously and linearly to $23 \cdot 3 \pm 3 \cdot 1 \mathrm{ng} / \mathrm{l}$ at the end of the infusion. At $1 \mathrm{~min}$ after the single injection of $1 \mathrm{i} . \mathrm{u} ., \mathrm{O}^{\prime} \mathrm{T}$ concentrations had increased to $55 \cdot 8 \pm 11 \cdot 3 \mathrm{ng} / \mathrm{l}$. Fig. $2(b)$ shows typical results for an individual cow.

Because no OT was administered before the start of milking, only a small amount of milk was removed during early milking $(1 \cdot 4 \pm 0.5 \mathrm{~kg}, 11 \pm 3 \%$, Fig. $2 b)$. Milk flow commenced again $1 \cdot 2 \pm 0 \cdot 1 \mathrm{~min}$ after infusion of OT had started. Plasma OT concentrations at commencement of milk flow were $5 \cdot 7 \pm 0.5 \mathrm{ng} / \mathrm{l}$. During the infusion of OT, most of the milk stored in the udder was removed $(8 \cdot 3 \pm 0 \cdot 6 \mathrm{~kg}$, i.e. $78 \pm 7 \%$ ). The remaining small fractions of milk were removed in response to injections of 1 and 10 i.u. OT. 


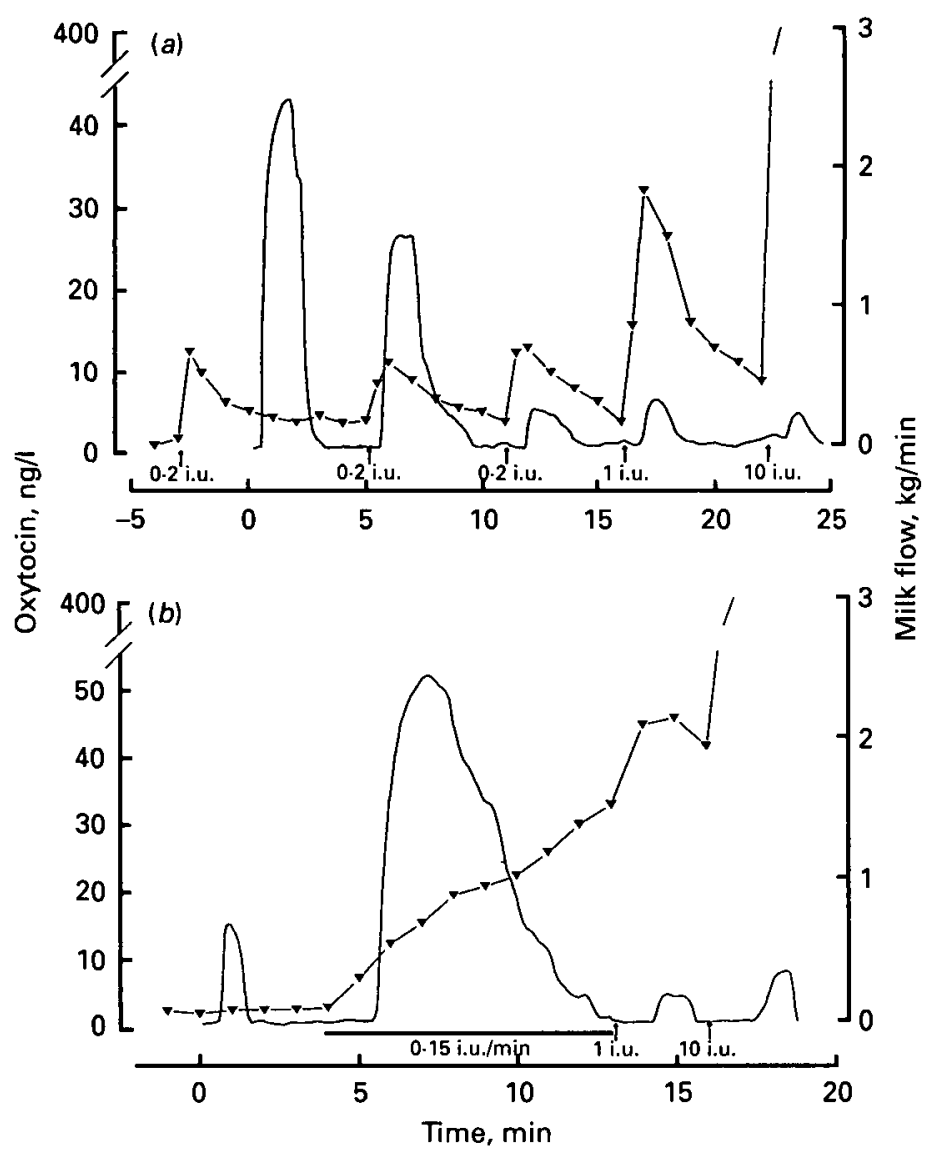

Fig. 2. Oxytocin concentrations $(\nabla)$ and milk flow rate $(-)$ of one cow in unfamiliar surroundings in response $(a)$ to repeated oxytocin injections (Treatment 2.1 ) and $(b)$ to oxy tocin infusion (Treatment 2.2). For details of treatments, see text. $\uparrow$, Individual oxytocin injections; - , continuous oxytocin infusion.

Treatment 2.3. Oxytocin injections during recording of IMP. Plasma concentrations of OT (Fig. 3a) increased in a dose-dependent manner after each injection. Preinjection concentrations increased slightly but significantly during the course of the experiment.

The IMP (Fig. $3 a$ ) increased after the first injection of $0 \cdot 2$ i.u. OT to a plateau. As in Treatment 1.2, IMP then decreased to another intermediate plateau. In response to the succeeding injections $(0 \cdot 2,0 \cdot 2$ and $0 \cdot 5$ i.u. OT), similar maximum and intermediate IMP plateaux were obtained. After injection of $1 \mathrm{i.u}$. OT the pressure increase was not significantly higher than after the $0 \cdot 2$ i.u. injections, but after injection of $10 \mathrm{i} . u$. OT, a higher peak pressure was achieved than after the previous injections of 0.2 i.u. OT $(P<0.05)$.

The lag time from injection of OT to commencement of pressure increase (Fig. $3 a$ ) was similar in response to all OT injections $(0.25 \pm 0.03 \mathrm{~min})$. The duration of the increase was $0.70 \pm 0.05 \mathrm{~min}$ in response to the first injection and was similar $(0.40 \pm 0.04 \mathrm{~min})$ after the other injections. The duration of the maximum in response to injections of $0 \cdot 2,0 \cdot 5$ and $1 \mathrm{i} . \mathrm{u}$. OT was $0 \cdot 90 \pm 0 \cdot 07,1 \cdot 10 \pm 0 \cdot 10$ and $1 \cdot 62 \pm 0 \cdot 14 \mathrm{~min}$ respectively, the last being greater $(P<0.05)$. In response to $10 \mathrm{i} . \mathrm{u}$. OT, IMP remained at the maximum for $>10 \mathrm{~min}$. 


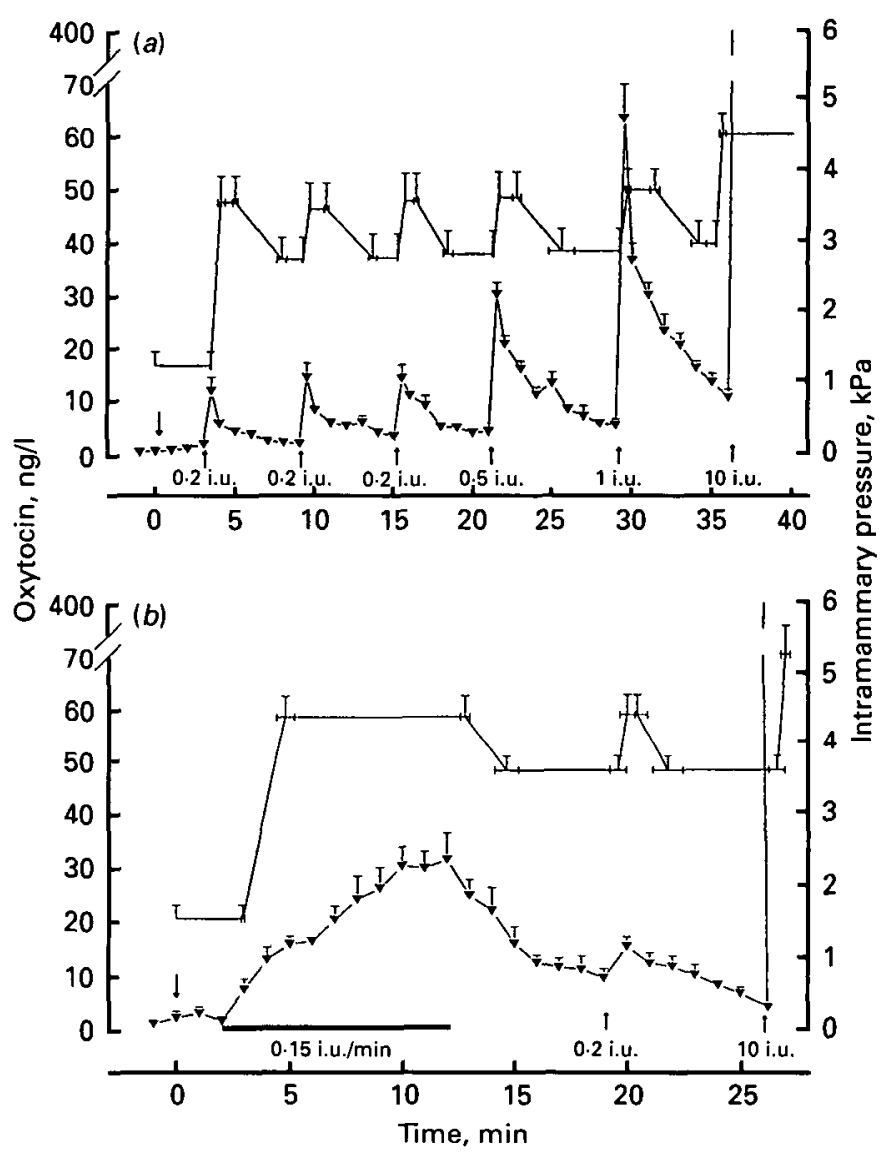

Fig. 3. Mean oxytocin concentrations $(\boldsymbol{\nabla})$ and mean pattern of intramammary pressure $(\longrightarrow)$ in cows in unfamiliar surroundings in response $(a)$ to repeated oxytocin injections (Treatment 2.3) and $(b)$ to oxytocin infusion (Treatment 2.4). For details of treatments, see text. $\downarrow$, Teat cannulation; $\uparrow$, individual oxytocin injections; - , continuous oxytocin infusion.

Treatment 2.4. Oxytocin infusion during recording of IMP. The concentration of OT (Fig. $3 b$ ) remained basal until infusion of OT was started. During the infusion period (10 min), OT plasma concentration increased continuously and linearly, and started to decrease immediately after infusion was stopped. Succeeding injections of $0 \cdot 2$ and 10 i.u. OT caused the expected increases in OT plasma concentration.

The IMP (Fig. $3 b$ ) remained stable before OT was infused and began to increase at $0.92 \pm 0.08 \mathrm{~min}$ after the start of infusion. At the commencement of pressure increase, OT concentration was $7 \cdot 4 \pm 1.9 \mathrm{ng} / \mathrm{l}$. The duration of IMP increase was $1.88 \pm 0.29 \mathrm{~min}$, i.e. more than double that in response to OT injection (Treatment 2.3). The IMP maximum remained stable until the infusion was stopped, and started to decrease at $0.80 \pm 0.21 \mathrm{~min}$ after the end of infusion. At this time, the OT concentration (calculated by interpolation) was $21 \pm 4 \mathrm{ng} / \mathrm{l}$. After the injection of $0 \cdot 2$ i.u. OT, IMP increased again to a maximum similar to that during infusion. In response to injection of 10 i.u. O'T a higher IMP peak was obtained $(P<0.05)$.

\section{DISCUSSION}

Concentrations of OT after injections or infusions were comparable to those found in other investigations (Wachs et al. 1984; Bruckmaier et al. 1992). Injections of $0 \cdot 2$ i.u. OT were found to cause plasma OT concentrations of 9-15 $\mathrm{ng} / \mathrm{l} 1 \mathrm{~min}$ after 
the injection, which is in the range of physiological OT release during milking (Schams et al. 1984, Mayer et al. 1984a,b, 1991; Bruckmaier et al. 1992). After injection of 0.5 and $1 \mathrm{i} . \mathrm{u}$. OT, plasma OT concentrations were in the upper physiological range, whereas after injection of $10 \mathrm{i} . \mathrm{u}$. O'T concentrations increased to supraphysiological levels. In both experiments concentrations of endogenous OT remained basal during milking and IMP recording, and this is important, because elevated OT concentrations occurred only after administration of exogenous OT and the disappearance time of OT was similar after injections before and during milking. Disappearance time of OT was comparable to that found by Wachs et al. (1984).

Only $\sim 10 \%$ of milk, obviously the cisternal milk fraction, was removed if the milking cluster was attached without previous OT administration (Treatment 2.2). Cisternal milk fractions of cows in unfamiliar surroundings have previously been found to be $5-10 \%$ of the total milk (Bruckmaier et al. 1993, 1994). Because of this small amount of cisternal milk, which is removed immediately by the milking machine, prestimulation is essential in milking practice to avoid blind milking. Only if OT release is stimulated before milk removal begins does opportune alveolar milk ejection occur (Mayer et al. 1984b; Gorewit \& Gassman, 1985).

If OT was injected $3 \mathrm{~min}$ before milking, OT concentrations (Treatments 1.1 and 2.1) increased transiently and were already close to basal when milking started. About $50 \%$ of the milk stored in the udder could be removed during subsequent milking, owing to partial ejection of alveolar milk, which is made possible by enlargement of the cisternal cavities (Bruckmaier \& Blum, 1992). In corresponding treatments with recording of IMP (Treatments 1.2 and 2.3), the IMP increased to a (physiological) maximum after the first injection of OT and did not increase beyond this maximum in response to succeeding 'physiological' amounts of OT. Therefore, if no milk was removed, all the alveolar milk could not be ejected because of limited space in the cistern. Only if milk was removed, and OT level was again elevated, were further portions of alveolar milk ejected.

Only a supraphysiological amount of OT (10 i.u.) was able to elicit an IMP increase to a higher level than the 'physiological' injections. This high dose of OT can obviously induce an additional contraction of the myoepithelial cells and therefore alveolar milk is ejected more completely than by concentrations in the physiological range. During removal of residual milk by supraphysiological amounts of O'T after normal milking, up to $30 \%$ additional milk was available (Rajamannan et al. 1966; Andreae \& Pfleiderer, 1972; Bruckmaier, 1988).

An OT level able to induce maximum milk ejection was reached after the first injection. Although no milk was removed during IMP recording, IMP decreased from its maximum plateau to another intermediate plateau when OT concentration decreased towards basal concentration. The duration of the IMP maximum was dependent on the OT dose. Because ejected milk is not likely to move back into the alveolar tissue, we assume that maximum IMP consists of two components, the pressure induced by the amount of milk present in the cistern, and the pressure contributed by the myoepithelial contraction. The IMP component, caused by myoepithelial contraction, disappears when plasma OT decreases towards basal concentrations. This would explain why in experiments with OT injections (Treatments 1.1 and 2.1) milk flow stopped after ejected milk was removed. In these experiments, no more milk was ejected when OT concentrations were too low to induce contraction of the myoepithelium. Thus, in experiments with a delayed start of milking after prestimulation (Mayer et al. 1984a; Rasmussen et al. 1992) the negative effects on milk flow and milk yield were possibly in part caused by 
transiently interrupted milk ejection due to decreasing OT concentrations after prestimulation. If concentrations of OT have already decreased to basal levels after prestimulation, $\mathrm{OT}$ release and myoepithelial contraction must be newly evoked by the teatcup liner to refill the cisternal cavities during milk removal and to keep the IMP at a high level until the end of milking. High IMP is important to keep the teat cistern completely filled within each pulsation cycle.

Incomplete alveolar milk ejection in response to different stimuli, as observed in catheterized teats (Mielke, 1963; Wehowsky et al. 1986), is also most probably due to OT concentration decreasing towards basal values after the end of stimulation.

If OT was infused (instead of injected) after the cisternal milk fraction was removed, plasma concentration of OT increased continuously. Milk ejection and milk flow started. Most of the milk was removed during the infusion, because only small amounts of milk were removed in response to subsequent injections of 1 and 10 i.u. OT, which elevated the plasma OT concentration into the high physiological and supraphysiological ranges respectively (Treatment 2.2). In corresponding trials with OT infusion and IMP recording (Treatment 2.4), IMP started to increase at an OT concentration similar to that at which milk flow started during OT infusion, and remained at the maximum level until the end of infusion. In other words, if OT concentration stays continuously elevated, as is found in normal milking practice, the contraction of the myoepithelial cells is maintained until the alveolar milk is completely ejected.

As soon as the IMP maximum was reached, IMP remained unchanged although OT concentrations increased during the whole period of infusion. This supports the notion that a threshold level of OT must be reached for maximal alveolar milk ejection, as postulated by Schams et al. (1984). However, the duration of IMP increase was much longer during infusion (Treatment 2.4) than after injection of OT (Treatment 2.3). Obviously, partial milk ejection (and partial IMP increase) during OT infusion began when concentrations of OT were slightly elevated and continued with increasing $\mathrm{OT}$ concentration until the threshold level for maximal milk ejection was reached. During further increase of OT beyond this threshold level IMP remained stable.

During infusion of OT, the IMP started to increase at OT concentrations $<10 \mathrm{ng} / \mathrm{l}$. This demonstrated high sensitivity to OT. In contrast, IMP started to decrease within $2 \mathrm{~min}$ after infusion of OT was stopped, although plasma concentrations of OT were still at $\sim 20 \mathrm{ng} / \mathrm{l}$ at this time. This indicated development of desensitization of the myoepithelium to OT during the course of infusion. On the other hand, IMP increased again to its maximum in response to an injection of OT $(0 \cdot 2$ i.u.) only $7 \mathrm{~min}$ after infusion was stopped, suggesting a resensitization if plasma OT decreased towards basal levels.

The lag time from injection of $\mathrm{O} T$ until the beginning of milk flow was closely correlated with the amount of milk actually removed in response to the injection, i.e. lag time increased with decreasing amount of milk. This correlation existed between animals and also within an animal when the amount of milk became smaller in response to a subsequent OT injection of the same dosage. If milk alveoli are less full, they probably need to contract further to shift milk into the cistern. Therefore it takes more time before milk ejection can be recorded in the cistern. This finding is in accordance with previous experiments (Mayer et al. 1991) in which milk ejection induced by teat stimulation was retarded at the end of lactation, although OT release in response to teat stimulation was enhanced. In contrast, lag time from OT injection until milk ejection was not retarded in response to succeeding injections in IMP 
experiments, because no milk was removed and milk remained in the alveoli after the first milk ejection.

In conclusion, during normal milking only $\sim 50 \%$ of the total amount of milk can be ejected by premilking milk ejection in early and mid lactation. The remaining alveolar milk fraction is ejected during the course of milking. An essential condition for continuous milk ejection during milking is continuous contraction of the myoepithelium induced by continuously elevated OT concentrations during the whole milking procedure. The original biological purpose of lactation is the nutrition of the suckling calf. Therefore, it is advantageous for the cow that milk ejection stops after the calf has suckled. As a consequence, cisternal cavities and teat sphincter are only transiently exposed to high IMP.

This study was supported by the Swiss National Science Foundation (Grant no. 32-28781.90). We thank Mr F. Jans, Eidg. F. A. Posieux and Dr W. Leuenberger, Affoltern i.E. for referring the animals. The help of Dr P.-Y. Vacher during the animal experiments and the expert performance of the oxytocin assay by Ms $G$. Bachmeier are greatly appreciated.

\section{REFERENCES}

Andreat, L. \& Pfleiderer, U.-E. 1972 [Residual milk as a criterion of udder emptying in cows kept in tieup type and cubicle-type cowsheds.] Milchwissenschaft 27 629-634

Bruckmater, R. M. 1988 [Oxytocin Release, Intramammary Pressure and Milk Production in the Cow in Relation to Stage of Lactation and Effect of the Adrenergic System.] Thesis, Technische Universität München, Weihenstephan, Germany

Bruckmater, R. M. \& BLUM, J. W. 1992 B-mode ultrasonography of mammary glands in cows, goats and sheep during $\alpha$ - and $\beta$-adrenergic agonist and oxy tocin administration. Journal of Dairy Research 59 151-159

BruCKMAIER, R. Ml., MAY ER, H. \& SCHAMs, D. 1991 Effects of $\alpha$-and $\beta$-adrenergic agonists on intramammary pressure and milk flow in dairy cows. Journal of Dairy Research $58411-419$

BrUCKMaler, R. MI., Rothenanger, E. \& BluM, J. W. 1994 Measurement of mammary gland cistern size and determination of the cisternal milk fraction in dairy cows. Milchwissenschaft In press

Bruckmater, R. M., Schams, D. \& Buum, J. W. 1992 Aetiology of disturbed milk ejection in parturient primiparous cows. Journal of Dairy Research 59 479-489

Bruckmater, R. M., Sснams, D. \& Blum, J. W. 1993 . Nilk removal in familiar and unfamiliar surroundings: concentrations of oxytocin, prolactin, cortisol and $\beta$-endorphin. Journal of Dairy Research $60449-456$

Gorewit, R. C. \& Gassilan, K. B. 1985 Effects of duration of udder stimulation on milking dynamics and oxytocin release. Journal of Dairy Science 68 1813-1818

Gorewit, R. C., Svenners'ten, K., Butlek, W. R. \& Uvnäs-Moberg, K. 1992 Endocrine responses in cows milked by hand and machine. Journal of Dairy Science $75443-448$

Lefcourt, A. M. \& Akers, R. M. 1991 Teat stimulation-induced oxytocin and catecholamine release in pregnant and lactating Holstein heifers. Domestic Animal Endocrinology 8 235-243

MAYER, H., BRLCKMAIER, R. M. \& SCHAMS, D. 1991 Lactational changes in oxytocin release, intramammary pressure and milking characteristics in dairy cows. Journal of Dairy Research 58 159-169

Mayer. H., SChams, D., Prokopp, A. \& WorstorfF, H. 1984 a Effects of manual stimulation and delayed milking on secretion of oxytocin and milking characteristics in dairy cows. Milchwissenschaft 39 666-670

Mayer, H., Schans, D., Worstorff, H. \& Prokopp, A. $1984 b$ Secretion of oxytocin and milk removal as affected by milking cows with and without manual stimulation. Journal of Endocrinology 103 355-361

MaYer, H., Worstorff, H., SCHams, D. \& KLeIN, M. 1985 Secretion of oxytocin and milking characteristics in cows as affected by several modes of tactile teat stimulation. Milchwissenschaft 40 1-5

Mielke, H, 1963 [Fractionated oxytocin release and milk ejection in the lactating cow.] Archiv für Experimentelle Veterinärmedizin 17 73-90

Rajamannas, A. H. J., Linverud, A. C. \& Graham, E. F. 1966 Lactation studies. IX. Relationship of milk flow rate and complementary milk to milk yields in a herd of Holstein cattle. Journal of Dairy Science 49 $32-35$

Rasmlssen, M. D., Frimer, E. S., Galton, D. M. \& Petersson, L. G. 1992 The influence of premilking teat preparation and attachment delay on milk yield and milking performance. Journal of Dairy Science 75 $2131-2141$

SaGi, R. Gorewit, R. C., Merrull, W. G. \& Wilson, D. B. 1980 Premilking stimulation effects on milking performance and oxytocin and prolactin release in cows. Journal of Dairy Science 63 800-806

SAS 1990 SAS Users' Guide: Statistics. Cary, NC: SAS Institute 
Schams, D. 1983 Oxytocin determination by radioimmunoassay. III. Improvement to subpicogram sensitivity and application to blood levels in cyclic cattle. Acta Endocrinologica 103 180-183

Schams, D., MaYer, H., Prokopp, A. \& Worstorff, H. 1984 Oxytocin secretion during milking in dairy cows with regard to the variation and importance of a threshold level for milk removal. Journal of Endocrinology $102337-343$

WACHS, E. A., Gorewit, R. C. \& CURrie, W. B. 1984 Half-life, clearance and production rate for oxytocin in cattle during lactation and mammary involution. I. Domestic Animal Endocrinology $1121-140$

WeHOwsky, G., Mority, P., TrögER, F. \& LOHR, H. 1986 [Deliberate initiation of incomplete alveolar milk ejections for determining the effect of stimuli.] Wissenschaftliche Zeitschrift der Karl-1/arx-Unicersität Leipzig, Mathematisch-Naturwissenschaftliche Reihe 35 273-282 